\title{
LA ETAPA CLARETIANA DE J. D. GARCÍA BACCA. CONTRASTE DE INTERPRETACIONES
}

\author{
CARLOS BEORLEGUI \\ Universidad de Deusto
}

\begin{abstract}
RESUMEN: Hasta la publicación del libro de Jorge M. Ayala sobre los años que García Bacca permaneció en la institución claretiana, sabíamos muy poco sobre esa fase de la vida del filósofo hispanovenezolano. Los datos que aporta Ayala sobre estos años resultan claves para conocer mejor su vida. Pero el enfoque desde el que Ayala ha escrito su libro limita de una forma importante los incontestables logros que contiene. El objeto de este artículo es desmontar muchas de las apreciaciones y juicios que Ayala proyecta sobre García Bacca, así como sobre todo el sesgado horizonte interpretativo desde el que enfoca los sucesos de la guerra civil española y las muchas víctimas que causó, sobre todo entre los religiosos claretianos.
\end{abstract}

PALABRAS CLAVE: Ayala; García Bacca; guerra civil; mártires; víctimas; neotomismo; horizonte interpretador; Confesiones.

\section{The Claretian stage of J. D. García Bacca. Contrast of interpretations}

ABSTRACT: Until the publication of Jorge M. Ayala's book about the years in which García Bacca stayed in the Claretian institution, we knew very little about that stage in the life of the SpanishVenezuelan philosopher. The data provided by Ayala about these years are key to knowing better about his life. But the approach Ayala takes in his book significantly limits the irrefutable achievements it contains. The aim of this paper is to dismantle many of Ayala's views and judgements about García Bacca and, particularly, the bias in his interpretative approach to the events of the Spanish civil war and the many victims it caused, especially among Claretian members.

KEY WORDS: Ayala; García Bacca; civil war; martyrs; victims; neotomism; interpretative approach; confessions.

INTRODUCCIÓN.

Desde que Jorge M. Ayala publicó su libro sobre García Bacca (GB), J. D. García Bacca. Biografía intelectual (1912-1938)², y lo leí con detenimiento, me he sentido obligado moralmente a expresar por escrito y públicamente mi opinión, dada mi condición de estudioso y especialista en GB. Pero no lo he podido hacer antes, impedido por otras tareas. El autor ya me advirtió que quizás me iban a extrañar algunos aspectos y su interpretación de la trayectoria de GB en sus años de claretiano, y efectivamente así ha sido. Hay muchas

1 Madrid, Ediciones Diálogo Filosófico, 2004. En realidad, el subtítulo del libro resulta inadecuado, en la medida en que, más que ser una biografía intelectual, se trata de una biografía existencial y vital de esos años anteriores a la guerra civil. Parece que el autor ha optado por este subtítulo remedando el de las Confesiones del propio García Bacca. Pero el subtítulo de las Confesiones. Biografía intelectual, es el título de la segunda parte de esa publicación, que no es otra cosa que un artículo publicado con antelación en la Revista Anthropos de Barcelona (1982, $\mathrm{n}^{\circ}$ 9). 
opiniones de Ayala sobre esa etapa de la vida de GB que considero no atinadas ni adecuadas. En su momento, le escribí a Ayala indicándole que el libro me había servido tanto para conocer mejor a GB como para conocerle a él, y expresé mis primeras opiniones en una breve recensión ${ }^{2}$. La verdad es que el libro es el resultado de una cuidada labor investigadora, que aporta una gran cantidad de documentación imprescindible para poder seguir la trayectoria vital de GB durante estos años. Pero, al mismo tiempo, el texto está salpicado de interpretaciones e impresiones personales (apoyadas en otras de diversos compañeros de institución religiosa, los claretianos) que resultan, en mi opinión, muy discutibles, y en algunos casos injustas. Considero que este conjunto de interpretaciones forman un horizonte interpretativo que entiendo es deudor de una mentalidad muy conservadora sobre la guerra civil y la actitud de la Iglesia en la misma, horizonte que desfiguran la visión que se nos presenta de GB.

Un libro tan extenso como el de Ayala (330 págs.) no puede tener su réplica más que en otro de similares proporciones. Por eso, en un texto como el presente, limitado en su extensión, no puedo hacer más que referirme a los aspectos que considero más importantes. Por tanto, iré conjugando tanto referencias a detalles concretos de la vida de GB, como a la interpretación global desde la que ha realizado la investigación Ayala. Como se verá, nos hallamos ante un serio conflicto de interpretaciones.

\section{El DETONANTE DEL LiBRo}

Como indica el propio Ayala, el detonante que le empujó a escribir este libro fue la publicación de las Confesiones. Autobiografía íntima y exterior de $\mathrm{GB}^{3}$, tras su muerte en agosto de 1992 (Quito, Ecuador). Como se sabe, GB nació en Pamplona el 1901, y tras unos breves años en San Sebastián y en Borja (Zaragoza) $)^{4}$ entró en el seminario claretiano de Alagón (Zaragoza, 1912), llegando más adelante a ser ordenado sacerdote, permaneciendo en la orden claretiana hasta abandonarla a finales de 1938, en París, iniciando su exilio en Latinoamérica. El propio autor nos dice $(\mathrm{A}, 10)^{5}$ que si GB no hubiera escrito sus Confesiones, en donde hace referencia de forma bastante negativa, y a veces

Cfr. Letras de Deusto, vol. 39 (2009), n 124, pp. 241-243.

3 Barcelona, Anthropos, 2000. El subtítulo de esta publicación hace referencia a los dos textos que contiene el libro. El más amplio, el que nos interesa aquí, se titula Confesiones de y por Juan David García Bacca; el segundo, Autobiografía «exterior», es un escrito ya publicado anteriormente, con el título Autobiografía intelectual, en la revista Anthropos (Barcelona), 1982, no 9, pp. 4-10.

4 Cfr. Beorlegui, C., «El maestro de niños Juan Isidro García Barranco, padre de Juan David García Bacca. Documentos y vicisitudes de su vida», Letras de Deusto, vol. 36 (2006), $\mathrm{n}^{\circ} 113$, pp. 211-244.

5 Las referencias al libro de Ayala las haré dentro del texto, poniendo entre paréntesis «A»(Ayala) y el número de página correspondiente. 
despectiva, a sus años de claretiano y a su salida de la orden, no se habría lanzado a escribir este libro y a dar a conocer al público diversos episodios de esta época, en la que supuestamente GB no queda demasiado bien. Ante el enfoque que GB hace de estos años, Ayala (y algunos de sus compañeros de congregación que le han ayudado) considera que no puede quedarse en silencio, sino presentar muchos datos nuevos y un enfoque diferente.

Podríamos estar de acuerdo con Ayala cuando indica que el estilo de las Confesiones invita a considerar el libro como una obra menor, y no a la altura del resto de su producción escrita. Es posible que este escrito no fuera para GB más que una especie de apuntes telegramáticos, que quizás no pensó nunca publicar, o sólo tras trabajarlo más a fondo. Más parece un cuadro pictórico hecho a brochazos gruesos, llenos sí de mucho sentimiento y pasión, pero sin la precisión y cuidado a la que estamos acostumbrados en otros de sus escritos. Tampoco sabemos nada sobre cuándo la escribió. Por la continuidad que tiene, no parece ser un diario que fuera escribiendo poco a poco, sino algo hecho de un tirón en los últimos años de su vida. Su hijo mayor, Francisco ${ }^{6}$, nos indica cómo al morir su padre en agosto de 1992, reunida toda la familia ante el cadáver, leyeron de un tirón el manuscrito de las Confesiones que Fany Palacios, esposa de GB, había recibido de él con «instrucciones (...) de entregárnoslas después de su muerte». No parece que GB tuviera intenciones de que se publicaran. Tampoco que lo prohibiera. Lo que sí dice Francisco es que «bastante nos costó hacer públicas las Confesiones, casi ocho años».

El libro de Ayala nos proporciona una serie de datos de importancia capital para conocer mejor esta etapa clave de la vida de GB, así como también del conjunto de su trayectoria vital, en toda su amplitud. Se trata de una época de su vida, sea cual sea la valoración que sobre ella hagamos, clave para entender todo el resto de la misma. Los aspectos más valiosos del libro de Ayala son, en primer lugar, la aportación de muchos detalles íntimos de la biografía de GB, dentro de la trayectoria de su periplo formativo y de los primeros pasos de su vida adulta, tanto en el aspecto personal como profesional. Detalles tanto más interesantes cuanto que se extraen en gran medida de las muchas cartas que se conservan del propio GB, en un amplio intercambio epistolar con sus superiores. En ellas aparecen fechas y contenidos que nos iluminan sus viajes a Munich, y posteriormente a París, Lovaina y Friburgo (Suiza). En esas cartas se puede apreciar la pasión extraordinaria con la que se dedica al estudio y a aprender de otros centros superiores de estudio, con objeto también de aplicarlo en los seminarios claretianos de la provincia de Cataluña. Esta pasión no la abandonará nunca, ni siquiera en medio del conflicto de la guerra civil.

El libro nos presenta también en diversos momentos la interesante y compleja relación de nuestro filósofo con el neotomismo, desde sus primeros

6 Cfr. García Palacios, Francisco, «Semblanza humana de J. D. García Bacca», en Beorlegui, C./de la Cruz, Cr./Aretxaga, R. (Eds.), El pensamiento de J. D. García Bacca, una filosofía para nuestro tiempo, Bilbao, Universidad de Deusto, 2003, pp. 47-56; cfr. p. 52. 
contactos, la evolución posterior, y el progresivo alejamiento del mismo. Es un aspecto que resulta fundamental aclarar, porque se nos hace ver en el libro las soterradas, y a veces claras y explícitas, sospechas que sobre GB se cernían entre algunos de sus compañeros de orden sobre su distanciamiento del tomismo, con acusaciones de que lo defendía sobre todo para cubrir las apariencias, cuando en realidad supuestamente estaría ya muy lejos de defender la filosofía del aquinatense. Y es cierto que progresivamente el suelo filosófico (utilizando la expresión del propio GB en otros escritos ${ }^{7}$ ) de nuestro autor fue variando del tomismo inicial a otra órbita filosófica conformada sobre todo por el raciovitalismo orteguiano y el historicismo diltheyano ${ }^{8}$. La transición del tomismo al vitalismo historicista de los primeros años fue compleja y poco transparente, como no podía ser menos dado el ambiente de obligada ortodoxia tomista a la que se hallaban sometidos los seminarios religiosos de todas las instituciones eclesiásticas de esa época. Es un tema demasiado complejo como para que nos podamos detener aquí y analizarlo.

Otro aspecto de gran interés y valía son las referencias a los diferentes pasos y movimientos de acercamiento de GB a la Universidad de Barcelona, comenzando por los exámenes para conseguir el título de Bachiller, seguido por el de Licenciado en filosofía, para lograr posteriormente el doctorado. El seguimiento de sus cartas intercambiadas entre GB y algunos de sus superiores nos sirve de ayuda inestimable para seguirle paso a paso en este itinerario. Igualmente, se advierte desde el primer momento tanto la alta valoración que le tienen los profesores de la Universidad, como el empeño ilusionado con que GB se dedica a asentarse como profesor titular de una Universidad pública, viendo en ello un paso adelante para poder influir en ella tanto en el terreno científico-filosófico como en el teológico y religioso. Igualmente, resulta esclarecedora toda la documentación que se aporta sobre su relación con el CEU de Herrera Oria, así como las diferentes valoraciones que tiene sobre el mismo: positivo en su primer momento de aceptación de impartir clases en dicho centro universitario, pero muy crítico en un momento posterior, cuando se encuentra ante la tesitura de tener que elegir entre su puesto en Barcelona o pasar a tiempo completo al CEU, dado que se le hacen incompatibles los dos puestos, y va descubriendo los aspectos personales menos atractivos de Herrera Oria, así como la endeblez de su incipiente centro académico.

Si todos estos aspectos son de gran interés, lo son mucho más los que se advierten a lo largo de su amplia correspondencia sobre su relación con los superiores y compañeros de institución durante esa amplia etapa de su vida (nada menos que 26 años, desde 1912 a 1938). De igual modo, se aportan datos de suma importancia sobre la evolución de su pensamiento y de su opción vital hacia los ideales políticos republicanos, paralelo a su alejamiento de

\footnotetext{
7 Cfr. GB, «Autobiografía intelectual», o.c.

8 Cfr. Beorlegui, C., García Bacca. La audacia de un pensar, Bilbao, Universidad de Deusto, 1988 , cap. $2^{\circ}$.
} 
la congregación claretiana, que fue el colofón de su progresivo vaciamiento espiritual, resultado de un amplio conjunto de factores que más adelante trataré de analizar de forma más amplia y concreta, con interpretaciones muy diferentes a las que presenta Ayala en su libro. De especial interés resultan también las páginas dedicadas a la época de la guerra civil, tanto en su estancia en Barcelona, como después en su permanencia en París, interrumpida con su corta estancia en Roma, hasta que se decide a dejar la orden y embarcarse hacia Quito, tras haber firmado un contrato de trabajo con su Universidad. Se trata de una documentación inestimable, que sirve de complemento y contraste a la que el propio GB nos presenta en sus Confesiones, y cuya conciliación con la documentación epistolar del mismo, y con otros documentos que Ayala presenta, no resulta fácil en algunos aspectos.

Todas estas aportaciones son tanto más valiosas por cuanto no están sólo hiladas y contadas desde fuera, sino que están acompañadas y llevadas de la mano de las cartas personales del propio GB, y de los diversos interlocutores con los que se cartea. En la medida en que toda esta valiosa e insustituible documentación sobre esta época vital de GB se halla en los archivos internos de los claretianos, sólo una persona como Ayala, claretiano y filósofo, profesor durante muchos años de la Universidad de Zaragoza, ya jubilado, y buen conocedor de la obra de GB, podía ser el instrumento que nos los diera a conocer. Cuando me encontraba redactando mi tesis doctoral sobre GB $^{9}$, intenté conectar con los archivos de los centros claretianos, para seguir su pista durante estos años, y me dijeron que ya no había quedado nada; quizás algo en los archivos de la Curia General en Roma. Ciertamente lo que ha quedado de GB en los archivos es, como puede verse, más de lo que parecía.

Es lógico que una institución no deje revisar sus archivos a cualquiera. Pero eso hace que la aportación que Ayala hace de esta interesante e ingente documentación, se vea un tanto empañada por un hecho evidente: en la medida en que sólo él ha tenido acceso a esos archivos (frente a los lectores, que nos tenemos que conformar con su palabra), y en la medida en que estamos muy lejos de coincidir con sus interpretaciones en muchos momentos del relato, nos entra una cierta incomodidad (no duda de manipulación de los textos, por supuesto) ante el hecho de que se nos muestra el panorama desde el punto de vista y el encuadre visual del autor. Es como cuando vemos un panorama o suceso cualquiera a través del encuadre de la cámara de TV. No es que sea falso, sino relativo, limitado. No tiene el lector posibilidad ni libertad de enfocar su mirada hacia aspectos que no están recogidos en el encuadre de la cámara. Pero es algo que no tiene remedio, y que ocurre con todo tipo de investigación. De todos modos, siempre me ha resultado evidente, ante la lectura del libro de Ayala, que el resultado habría sido muy diferente, así como la imagen final de

9 Cfr. Beorlegui, C., La filosofía del hombre en J. D. García Bacca, 2 vols., Bilbao, Universidad de Deusto, 1983. El texto fue publicado años después, muy retocado, con el título García Bacca. La audacia de un pensar, Bilbao, Universidad de Deusto, 1988. 
GB, si el autor hubiese cuidado más la objetividad y la distancia crítica. Ayala se ha proyectado, en mi opinión, de una forma excesiva en este proceso de investigación, produciéndose algo similar al giro que achacan en Antropología cultural a los antropólogos postmodernos: al mismo tiempo que nos cuentan los rasgos de la cultura que investigan, se hallan interesados en hablarnos de las circunstancias personales que han tenido que atravesar en el proceso investigador ${ }^{10}$. Con lo cual, resultan libros que nos hablan tanto o más del autor que del objeto a investigar.

\section{UNA TRAYECTORIA BAJO SOSPECHA PERMANENTE}

Desde la perspectiva de la salida de GB de la orden unos meses antes de acabar la guerra, Ayala va introduciendo una sospecha generalizada sobre casi todos los pasos de la estancia de GB entre los claretianos. Esto le da al libro un desagradable tono inquisitorial que le resta credibilidad, resultando incluso cómico en algunos aspectos.

\section{a) Enfoque de sospecha y acusación de mentira y ambigüedad}

Es verdad que GB en sus Confesiones, cuando hace balance general sobre su estancia entre los claretianos, mientras está viajando en barco hacia Quito, se expresa de forma muy dura y negativa: "estoy sentimentalmente seco», «me habían secado el alma» (C, 34), «me sentí libre por primera vez en mi vida» (C, 68), "había estado "secuestrado" progresivamente desde 1911 hasta 1928» (C, 69). Pero de ahí no se deduce que toda su vida entre los claretianos haya sido una farsa, que se expresa y aclara, por fin, cuando deja la institución para marcharse a América. Lo que está claro es que se ha producido en él una crisis tan honda que le sumerge en una ruptura total con toda su vida anterior, estemos o no de acuerdo con sus decisiones y valoraciones posteriores. Pero de ninguna manera resulta lógico querer ver por ello, desde el inicio de su entrada en la orden, unas intenciones torcidas e interesadas, como parece indicar Ayala en diversos momentos del libro. Ayala parece empeñado en hacernos creer que, por el hecho de que al final GB se identificó con las tesis sociales y políticas del republicanismo, y se fue alejando de sus creencias religiosas y de su adhesión a la orden claretiana, adoptando durante los años de la guerra una conducta ambigua e indecisa sobre qué camino seguir, este paso final ya estaba en la mente de GB desde mucho tiempo antes, empujándole a llevar una doble vida en muchos momentos, cosa que los hechos que él mismo relata y los testimonios de muchos de sus compañeros y de los que vivieron con él no hacen

10 Cfr. BARLEy, Nigel, El antropólogo inocente, Barcelona, Anagrama, 1989; Beorlegui, C., «La postmodernidad en la Antropología: de la objetividad (científica) a la retórica (literaria)», Letras de Deusto, 23 (1993), n ${ }^{\circ}$ 59, 65-86. 
más que desmentir. Nunca he entendido cómo no quiere aceptar Ayala que una cosa es que GB fue evolucionando y cambio de opinión y de valoración sobre muchas cosas, y otra muy distinta, que ese cambio se empezara a producir ya en fases en las que no hay datos objetivos, ni nada parecido, para que se pueda atribuirle una doble intención.

El autor nos está reiteradamente advirtiendo que nos hallamos ante un enfoque de la vida de GB totalmente distinto según se lea lo que GB nos dice en sus Confesiones y lo que ocurrió en realidad, como se va a encargar él de demostrárnoslo. Por eso, el autor no cesa de llamar la atención al lector sobre la supuesta doble intencionalidad de palabras y de conducta de GB, tratándolo en ocasiones poco menos que de mentiroso compulsivo. Lo curioso es que esta actitud parece desaparecer en la Conclusión final, donde el tono es más mesurado y valorativo, en contraste con el conjunto del libro, donde da la impresión de que, como digo, el autor adopta un enfoque de sospecha casi permanente, no dejando pasar ningún detalle ni ninguna ocasión de hacernos ver que GB se equivoca en muchos de los detalles que aporta sobre su biografía, y que incluso adopta una actitud de doble intención, de sospechosa, mentira e hipocresía.

Este talante narrativo influye también en el método que Ayala tiene de presentar los diversos hechos y documentos de la vida de GB. En muchos momentos lo lógico es que presente el hecho, la carta o el documento correspondiente, para después contraponer otras cartas u opiniones diferentes, y que el lector se forme luego su propia opinión. En cambio, en la mayoría de los casos, Ayala empieza dándonos su opinión y la de otros críticos, para después, cuando ya se ha sembrado la sospecha, aportar la carta de GB o el documento correspondiente. Un ejemplo muy claro de esto lo constituye el episodio del enfrentamiento con el obispo de Calahorra (A, 258-278). Después de muchas páginas en las que se analiza el hecho, con contrarréplicas y diversidad de opiniones (A, 258-267), puede por fin el lector leer el artículo publicado en la Voz de Madrid, y a continuación la carta de GB en la que se identifica como fuente de las confidencias del obispo (A, 268 y ss.). Parece un método inocente, pero he sentido esta incomodidad y desacuerdo con el procedimiento en las tres veces que he leído el libro con detenimiento. No acabo de ver que se trate de un método del todo limpio, porque refleja la clara intención del autor de orientar la opinión del lector, no dejándole que él juzgue por su cuenta.

En todo el libro se advierte con claridad, y el autor no hace ningún esfuerzo por ocultarlo (pienso que tiene todo el derecho del mundo a ello), una animadversión clara y directa con el conjunto de esta etapa de la vida de GB. El hecho de haber dejado la orden claretiana, abandonar el sacerdocio, e incluso desdecirse de su fe cristiana, parece ser motivo como para casi demonizarlo (es posible que sea un calificativo demasiado duro) y presentarlo ante el lector como una persona de la que no hay que fiarse. Ese final negativo le empuja a Ayala a ver aspectos sospechosos en muchos de los momentos anteriores de la vida de GB, ya desde el momento en que decide dejar su familia para entrar en la orden claretiana, en el colegio de Alagón. 
Por eso, me resultó casi emocionante la lectura, por inteligente y comprensiva, de la extraordinaria carta del P. Ortega, claretiano, en la que, tras haberse encontrado y hablado en Madrid con GB, le escribe a su superior claretiano dándole sus impresiones sobre el filósofo. Su tono empático, comprensivo y perspicaz de la situación en la que se hallaba GB nos lleva a pensar qué diferente habría sido este libro de Ayala si en vez de haberlo escrito con ese talante de sospecha, lo hubiera hecho con el que muestra el P. Ortega. Tendremos ocasión de volver sobre esta carta más adelante, porque me parece de gran valor para entender la situación en la que se hallaba nuestro filósofo, y por dónde podrían haber ido las cosas de haber habido alguien, o un entorno institucional, que le hubiera acompañado en su situación de soledad en la que la fina perspicacia del P. Ortega advierte se hallaba GB.

\section{b) Aspectos concretos de su vida}

Quiero a continuación referirme a algunos pasajes del libro, no todos, porque no cabrían en un escrito limitado como tiene que ser éste, en el que Ayala envuelve con sospechas acontecimientos de la vida de GB. Este talante se advierte ya al referirse al segundo apellido de GB, Bacca. Se trata de la primera página (A, 27, cap. II) del capítulo en el que va a presentarnos los datos familiares. Los documentos oficiales indican que el apellido de su madre era Vaca, mientras que el antes P. David García, tras la guerra, comenzará a presentarse como Juan David García Bacca. Ayala nos indica que este cambio lo ha hecho "por motivos que no ha explicado, pero lo sospechamos» (A. 27, subrayado mío). ¿Y qué hay que sospechar? ¿Por qué no pensar que una persona puede cambiar su nombre al inicio de una nueva etapa de su vida, cuando, como es el caso que nos ocupa, ese cambio ha sido tan fuerte y traumático?

En diversos momentos, Ayala le echa en cara que no haga referencia GB en sus Confesiones a determinados detalles de su vida que él considera que tendría que haberlos reseñado: el recuerdo del gran valor arquitectónico de la iglesia de Borja, donde ejerció de monaguillo (A, 30); sobre su vida personal y eventos religiosos de esos años (A, 30); «sobre su madre, dice Ayala, guarda un silencio sepulcral. Lo mismo hace con sus otros hermanos. Como si no los sintiera. Ni un rasgo de amor, de reconocimiento hacia la madre. Nada» (A, 3132 ); etc. Resulta sorprendente que Ayala haga estos juicios de valor tan duros simplemente porque GB no se explaya sobre ello en sus Confesiones. Parece como si Ayala le exigiera a GB seguir una serie de pautas sobre cómo redactar sus Confesiones. De hecho, en el capítulo I, Ayala se detiene en analizar este género literario, inaugurado con S. Agustín, pero con antecedentes en otros autores del mundo griego y latino. Ya hicimos referencia más arriba al hecho de que quizás GB nunca pensó, ni lo quiso tal vez, que se publicaran. Quizás por eso la redacción es más bien seca y telegramática, con una serie de limitaciones que el propio Ayala indica (A, 21). Reconoce también que GB «fue todo un caballero" y «dice mucho a su favor» (A, 22) al mantener en secreto la mayoría de los datos que refiere en su escrito, y dejarlo en manos de su mujer para que 
lo pudieran leer sus hijos tras su muerte. Ayala se aventura, una vez más, a sospechar que la redacción primera de este relato la tuviera in mente cincuenta años antes, «cuando pidió a la Santa Sede la reducción de sacerdote al estado secular» (A, 22). Esta puede ser la razón, según Ayala, de que GB mantuviera tan clara la mente y recordara con tanta exactitud los muchos datos que apunta en su relato sobre su vida entre los claretianos, en la medida en que los tomaría del Memorandum que redactó para su proceso de secularización (A, 22).

Pero, a pesar de esta buena memoria, y aunque en algunos datos se equivoca, lo que ve Ayala en este texto es un problema de veracidad (A, 23). Dice que «se trata de unas Confesiones selectivas» (A, 23). ¿Y qué Confesiones o Autobiografías, de las que tanto abundan en el presente, no lo son? La memoria es siempre selectiva. A menos que lo que se quiera decir es que GB escribiera su texto con el propósito de mentir ( «Las Confesiones de G.B resultan un tanto atípicas por su falta de sinceridad»: A. 23). Menos mal, está pensando Ayala, que no le sirvió de nada este truco, porque aunque «G. B. debió de pensar que no quedaban Claretianos que pudieran contrastar sus afirmaciones» (A, 23), sí quedaban algunos, y Ayala va recogiendo diversas opiniones de ellos para contraponerlas a las de GB, y hacernos ver que «muchas de sus afirmaciones y valoraciones encierran cierta tendenciosidad» (A, 23).

La verdad es que Ayala no ahorra esfuerzos para hacernos ver las diferencias y contrastes entre afirmaciones de las Confesiones y las opiniones de otros claretianos, incluso con afirmaciones que aparecen en cartas tanto de GB como de sus superiores. Pero esas diferencias valorativas se explican simplemente por el cambio de mentalidad producido en GB antes y después de pertenecer a los claretianos. Ayala sabe de sobra que esto se produce en toda persona que abandona un estilo de vida tan exigente como una institución religiosa. Lo hemos visto en los cientos y miles de sacerdotes y religiosos/as que desde hace ya varias décadas van dejando su estilo de vida para emprender otra, dándose un amplísimo abanico de posturas muy diversas cuando tratan de enjuiciarla (el refrán castellano ya lo dice: «cada uno habla de la feria, según le ha ido en ella»). Para unos, ha sido una prisión; para otros, una decepción; para otros, una etapa buena y provechosa de su vida, aunque después han querido emprender otra; etc. Así de simple. Se pueden enjuiciar estas decisiones y valoraciones desde muchos puntos de vista, incluso haciendo juicios morales sobre ello. Pero, además de correr el riesgo de ser injustos, perderíamos el tiempo en querer marcar pautas y juicios de valor que sirvan para todos. Lo que está claro es que lo que para GB, durante su estancia en la orden, fue algo que lo vivió con provecho y naturalidad (estoy totalmente de acuerdo con Ayala al afirmar que uno no está en una institución religiosa durante más de 25 años a la fuerza y sin el suficiente convencimiento, máxime cuando se ha pasado ya de los 30 años), posteriormente, desde una perspectiva existencial y cosmovisional diferente, lo percibe como opresivo, sin libertad ni autonomía, y sin interés en continuar.

Parecería como si Ayala esperara una mayor valoración por parte de GB de sus años transcurridos en los claretianos, o al menos no haber dejado ningún testimonio público de ello. Aunque así fuera, no resulta muy razonable la 
dureza con la que se refiere a hechos como las motivaciones que GB indica le llevaron a entrar en el seminario, tanto en las supuestas presiones psicológicas como en las motivaciones económicas, ocultando supuestamente, según Ayala, «los hechos reales: falta de medios económicos en la familia» (A, 32). Ayala parece estar empujado por la tendencia a pensar que todos los que entraron esos años en las instituciones religiosas, lo hicieron por motivaciones no limpias, en concreto, por necesidades económicas. Entiendo que, en este punto, los argumentos se vuelven en su contra, porque tenemos que volver a decir aquí que difícilmente se puede aceptar que una persona que entra en el seminario por razones económicas, se mantenga en él hasta casi los cuarenta años sólo por esas motivaciones iniciales. Considero superfluo decir, aunque parece que hay que hacerlo, que una cosa es que la situación de la familia de GB no fuera buena en lo económico (tras la muerte del padre, la viuda quedó sin apenas medios económicos, teniendo que dejar a varios de sus hijos a diversos parientes para que pudieran seguir adelante; y eso ocurría con la familia de un maestro), y otra cosa es decir que su madre casi le obligó a entrar en el seminario claretiano, con lo que de esa forma se ahorraba tener que mantenerlo. Las afirmaciones de Ayala, además de gratuitas, van en la línea de querer echar sobre su trayectoria todo tipo de sospechas, así como malas o indecorosas intenciones sobre GB. Todo esto se coronará, cuando GB esté a punto de abandonar la orden, con repetidas referencias de cara al lector para hacerle ver el desigual comportamiento entre GB y la congregación: ésta se lo ha dado todo, y GB le pagará con el abandono, en el momento en que podría aportar tanto a la institución que no había regateado nada para formarlo y prepararlo (A, 42). Uno sospecha que esta decepción puede estar al fondo de esta actitud tan dura con GB. Como si fuera un ajuste de cuentas. Pero con ello parecería que la solución tendría que ser quedarse en la institución, aunque el interesado sienta que ya no tiene razones para ello, en la medida en que no podrá pagar nunca la deuda que ha contraído con ella.

Hemos dejado claro ya que Ayala escribe su libro tras, y motivado por, la publicación de las Confesiones de GB. De ahí que trate de salir al paso de cada uno de los detalles que presenta GB, para desmentirlo o desvalorizarlo. Está claro que en el momento en que, desde el horizonte de sus casi 90 años, escribe GB sus Confesiones, ha transcurrido tanto tiempo y han evolucionado tanto las formas de pensar y de vivir, no sólo en el ámbito de las congregaciones religiosas sino también en el mundo laico, que se trata de críticas que hoy día pierden mucho su valor. El propio Ayala lo entiende así al decir que lo que relata GB «en lo intelectual y religioso» de los claretianos "puede resultar chocante». Ayala advierte que está claro que así es para una persona que no ha vivido aquello, e incluso "también para todos nosotros» (los religiosos actuales). Ello es así porque «ese ambiente era el que entonces se vivía en todas las Congregaciones y Órdenes religiosas de España, y que, con sus defectos, sirvió para formar grandes hombres de la cultura y de la Iglesia. También contribuyó a formarle a él, pues sin esa Congregación que le posibilitó todos los medios a su alcance para que realizara sus estudios, su vida hubiera sido muy distinta» (A, 23). 
Pues si esto es así, y estoy de acuerdo con ello, ¿por qué tomarse las afirmaciones de GB en sus Confesiones como si fuera un asunto contra el que hay que salir a defenderse con tanta agresividad y detalle cicatero, y no contentarse en realizar un juicio comprensivo (aunque también haya que ser crítico, sin ninguna duda) sobre las razones de GB al recordar aquellos años, que sirvieron efectivamente para formarse y posibilitarle llegar a ser lo que pudo más adelante ser, pero que también constituían años de amargura por no permitirle asimilar en su vida facetas que perseguía: apoyo al republicanismo, superación de la filosofía tomista, una mayor apertura a la laicidad y al pensamiento crítico ilustrado, y a la consecución de un tipo de fe que supiera dialogar sin complejos con la ciencia y la filosofía de su tiempo. Ese camino no lo pudo encontrar, y en ese empeño (con todos los reparos que se puedan poner) dejó la fe religiosa en el camino. Desde ese punto de vista se explica su amargura al recordar que no pudo estar en el entierro de su madre $(C, 11)$ (no entendemos de nuevo la dureza de los comentarios de Ayala, después de decir que era costumbre en todas las congregaciones no dejar visitar a sus padres en la etapa de formación, 37-38; 65 y ss.), y otras referencias muy críticas a diversos aspectos de la vida conventual, como el tipo de libros de textos y la metodología de estudio que utilizaban en el filosofado y teologado (A, 51 y ss.), sobre todo en el terreno de la Teología moral (A, 69 y ss.), etc. Vuelve también Ayala a reprocharle que haya olvidado la referencia a las órdenes menores, anteriores al sacerdocio (A, 79), teniendo de nuevo que recordarle que GB recoge lo que le parece importante para su relato desde su punto de vista; no escribe para dejar contento a Ayala ni a nadie. Pero ya es el colmo de la simpleza y de la ingenuidad cuando se extiende, al afirmar GB que no recuerda que ante su ordenación sintiese nada especial, en disquisiciones teológicas y psicológicas sobre la diferencia entre la eficacia objetiva de un sacramento y la faceta subjetiva del que lo recibe, para concluir tajantemente: «él sintió lo mismo que sus compañeros» (A, 80). ¿Quién sabe lo que sienten otros? GB lo que está haciendo es desahogarse, al revivir al cabo de tantos años esos acontecimientos, de los que se halla ahora tan lejano en tantos aspectos. Es una expresión subjetiva, contra la que no tenemos nada que objetar, aunque discrepemos.

Una vez ordenado, y arrastrando todavía su hemoptisis grave (A, 79), dolencia contraída en una de las excursiones montañeras colectivas, comienza su etapa de profesor de filosofía en el colegio de Solsona (A, 84) y sus primeras estancias de estudio en Alemania. Como he indicado en su momento, las aportaciones documentales del libro de Ayala sobre esto y sus otros viajes posteriores a París, Lovaina y Friburgo son de extraordinario interés, porque no sólo aportan fechas documentadas sino contenidos concretos y abundantes de esas estancias. Podríamos extendernos sobre aspectos de gran interés dentro de la vida de GB, como su relación con el neotomismo y las sospechas de algunos de sus compañeros sobre su ambigüedad calculada en este punto (A, 138-139), así como su extraordinario afán por el estudio que muestran sus cartas, donde parece que otro tipo de temática (la espiritual, por ejemplo) está siempre ausente (A, cap. VII y VIII), pero no podemos extendernos sobre ello aquí. 
Nos interesa más referirnos a la época en que GB se va introduciendo en la Universidad Autónoma de Barcelona y va comenzando su labor docente en ella, teniendo que dejar por ello su tarea de profesor de metafísica en Solsona (A, cap. IX). Es un salto con el que no todos sus compañeros de institución estaban de acuerdo, y el relato de Ayala sigue repleto de puntadas críticas sobre oscuridades, sospechas y ambigüedades, que tienen sentido a posteriori, cuando se interpretan desde su salida posterior de la orden, pero sigo pensando que no tienen fundamento y sentido desde la altura cronológica de los acontecimientos. Está claro que GB está lanzado en estos años a labrarse una carrera profesional, en la que ve una ventaja para él, para su congregación y para los intereses de la Iglesia y del cristianismo. Podemos volver a interpretarlo como un engaño, considerando que las razones sobre el interés de la congregación y de la presencia de un profesor cristiano en la universidad laica es pura tapadera para alcanzar sus propios objetivos empujados por su vanidad. Pero no pasa de ser una interpretación subjetiva, aunque, por otra parte, de un mínimo de vanidad no se libra nadie.

Es evidente que GB, en sus cartas a sus superiores religiosos, busca siempre conseguir sus objetivos, empleando los argumentos y palabras que sabe van a facilitar conseguirlos, pero no veo que se tenga que repetir permanentemente la sospecha, como hace Ayala, de zalamero y de cierta doblez (A, 121).

\section{LA ÉPOCA DE LA REPÚBLICA Y LA GUERRA CIVIL}

Antes de adentrarnos en el análisis de cómo narra e interpreta Ayala las vicisitudes de GB durante esta etapa, quisiera hacer varias apreciaciones globales sobre esta controvertida época de la historia de España. Entiendo que es fundamental hacer estas reflexiones previas porque considero que lo que me diferencia de Ayala es precisamente el distinto horizonte interpretativo del que partimos y juzgamos. De ahí que considero que, partiendo de un enfoque diferente de esta época, se puede hacer una valoración totalmente diferente de esta etapa de nuestro filósofo.

\subsection{El horizonte interpretativo de esta época}

Donde se advierte de forma particular el enfoque específico de Ayala a la hora de redactar su libro, y que nos lleva a considerar que el conjunto del mismo está totalmente desenfocado, es en el modo como Ayala interpreta el entorno de la guerra civil española. Podríamos decir, simplificando pero sin desenfocar la verdad, que para Ayala la guerra fue algo que resultó necesario e inevitable dado el odio anticlerical de una parte de la sociedad española, que persiguió a los obispos, curas y religiosos/as, y también a laicos católicos, ante la ineficacia y pasividad de un Gobierno de la República, que no supo o no quiso poner orden. Ante esa situación, y, como una acción de defensa de la propia existencia, la 
Iglesia oficial y gran parte de la sociedad española vio con buenos ojos, y apoyó el levantamiento militar de Franco (el alzamiento nacional), legitimando su postura y dando a la guerra el carácter de cruzada contra los enemigos de España y de la religión. Es verdad que Ayala acepta que al principio el levantamiento militar no tuvo motivaciones religiosas, pero que enseguida se justificó el alzamiento ante las matanzas y el sesgo anticlerical que adoptó la República (A, 260). En esta situación, la equivocación y la desgracia de GB fue ir inclinándose progresivamente hacia el bando republicano, como consecuencia de dejarse influir por profesores amigos de la Universidad de Barcelona, por el descuido del cultivo de su fe, y el afán excesivo por el cultivo de la filosofía y de la ciencia, posturas que le llevaron a mantener durante mucho tiempo una actitud ambigua e hipócrita, y, además, mantener también un silencio sospechoso e incomprensible ante la muerte de los mártires claretianos, muchos de los cuales habían sido compañeros o exalumnos. A todo eso hay que añadir, entre otros hechos, en opinión de Ayala incorrectos, la estancia en Barcelona durante los primeros momentos de la guerra, la filtración de las opiniones del obispo de Calahorra sobre el bombardeo de Gernika, la negativa a obedecer a sus superiores para regresar a España y reintegrarse en la vida universitaria, juntos a otras decisiones.

El planteamiento que yo voy a mantener es que este horizonte interpretativo, que ha sido el hegemónico durante la época franquista, y sigue defendiendo una parte de la derecha sociológica española, resulta incomprensible mantenerla en pleno siglo XXI, en la medida en que se opone a la mayoría de las investigaciones históricas más objetivas y con serios esfuerzos de neutralidad, que se han ido haciendo y se siguen publicando en la actualidad. Por ello, todo el esfuerzo que hace Ayala de describirnos la trayectoria de GB en estos años, se halla tan prejuiciosamente coloreado con este enfoque interpretativo, que limita de forma muy importante todo su trabajo.

Cuando se leen investigaciones sobre la guerra, tanto de historiadores españoles como de extranjeros, realizadas desde un esfuerzo serio por no dejarse llevar por sesgos ideológicos previos, los acontecimientos se nos muestran de forma muy diferente. A la hora de estudiar la guerra civil española de 1936-1939, el conflicto interpretativo sobre la dimensión religiosa de la guerra constituye todavía un aspecto fundamental, y más todavía para el caso que nos ocupa. No es fácil ponerse de acuerdo sobre muchos aspectos de esta guerra y sus años previos, no sólo porque los prejuicios ideológicos son difíciles de neutralizar, sino porque, como muchos historiadores señalan, la guerra civil fueron muchas guerras al mismo tiempo ${ }^{11}$, en la medida en que fue el resultado de, al menos, los siguientes enfrentamientos: una cultura urbana cosmopolita contra otra conservadora muy apoyada en ámbitos rurales; un modo de entender la vida desde una ética humanista frente a otra apoyada en

11 Cfr. Preston, P., «Prólogo» a Raguer, Hilari, La pólvora y el incienso. La Iglesia y la Guerra Civil española (1936-1939), Barcelona, Península, 2008 (2a ed.; la $1^{\text {a }}$ ed.: Barcelona, Bruguera, 1977), p. 17; Graham, Helen, Breve historia de la guerra civil, Madrid, Espasa-Calpe, 2006, pp. 18-19. 
una religiosidad muy conservadora; una visión liberal de la sociedad contra otra apoyada en el autoritarismo; un modelo centralizado de España frente a otro autonomista e independentista; y, por último, un modelo abierto de costumbres sociales, apoyado en un feminismo de una «nueva mujer», contra un modo tradicional y cerrado de entender los papeles de género ${ }^{12}$.

Y, al cabo de tres cuartos de siglo de finalizada la guerra, y ante la mayor posibilidad de ir consultando los archivos, parece que en muchos de los aspectos (económico, social, militar, etc.) que desencadenaron la guerra, se ha podido llegar, si no a consensos, al menos a un acercamiento de posturas. En cambio, como indica H. Raguer, «en el tema religioso siguen las lanzas enhiestas, no diré como en 1939, pero casi. No sólo se mantienen básicamente contrapuestas la visión de los vencedores y vencidos, sino que las pasiones se desatan más que al tratar de cualquier otro aspecto de la Guerra Civil. Son especialmente los defensores de la noción de cruzada y los promotores de los procesos de beatificación y canonización de mártires de la Guerra Civil los que cuando, después de tantos años de vocear su versión, llega a sus oídos otra distinta, reaccionan de modo muy poco científico, con suma agresividad $»^{13}$.

El bando vencedor tuvo gran empeño en presentar la guerra como una cruzada. Pero los historiadores han ido desmontando y relativizando este concepto, en la medida en que la motivación religiosa de la guerra, entendida como resultado de la persecución religiosa, no se dio desde el principio. Y sobre la persecución y matanza de sacerdotes y religiosos/as, los datos que se aportan nos hacen ver un panorama más complejo del que se extendió interesadamente en su momento ${ }^{14}$. No se trata de acumular referencias bibliográficas y amontonar datos que sobrepasarían un escrito como éste, sino de presentar tan sólo una serie de pinceladas al respecto. En relación a las motivaciones que llevaron a los militares a la rebelión contra el Gobierno legítimo de la República, se sabe que no fue precisamente el factor religioso sino otros los que les empujaron a rebelarse, como la oposición a los separatismos vasco y catalán, el rechazo del socialismo y comunismo incipientes, así como a unos modelos de vida y a unos valores liberales, que ponían en cuestión el principio de autoridad y las costumbres tradicionales ${ }^{15}$. La motivación religiosa vino después, producto precisamente del apoyo que los obispos españoles dieron al levantamiento de los militares rebeldes, advirtiendo muy pronto ambos, obispos y militares, el mutuo interés y las importantes ventajas que esta alianza les iba a proporcionar. De hecho, los estudiosos advierten que el levantamiento militar ni siquiera pretendió originar una guerra civil ${ }^{16}$, sino más bien realizar a un

12 Cfr. Graham, H., o.c., p. 19.

13 RAGUER, H., o.c., p. 22.

14 Cfr. Portales, P./Ubeda, Ll., «Memorias de las memorias: La represión anticlerical en Cataluña. Cómo ha llegado la información de aquellos meses de 1936 a sacerdotes y religiosos», Iglesia Viva, 2014, n 260, pp. 51-63.

15 Cfr. Raguer, H., o.c., cap. $3^{\circ}$.

16 Cfr. Raguer, H., o.c., p. 86 y cap. $3^{\circ}$. 
pronunciamiento, al estilo de los que el ejército español estaba acostumbrado a protagonizar a lo largo del siglo XIX, en línea con el papel que se había dado a sí mismo de garante del patriotismo y de la unidad española. Ahora bien, en la medida en que la resistencia del Gobierno de la República, apoyado en la parte fiel del ejército, comenzó a resistir, la estrategia de Franco fue, como se advierte en varios momentos del conflicto, alargarlo para purgar con tiempo y sin contemplaciones las diversas partes de España que habían apoyado el bando republicano, porque, tras el sesgo ideológico y religioso que fue cobrando la guerra, España debía de ser purificada, a través de un sacrificio sangriento ${ }^{17}$.

La motivación religiosa, como hemos indicado, se introdujo muy pronto, pero sólo en un segundo momento. El problema religioso en España venía de lejos, como consecuencia de que en nuestro país no se había producido el proceso ilustrado que se había desarrollado en casi todo el resto de Europa a lo largo del s. XIX. La España de comienzos de siglo vivía anclada en la herencia recibida del siglo anterior, cimentada en la lucha entre liberales y conservadores, con el dominio en lo religioso de una mentalidad profundamente reaccionaria, que apoyaba sin fisuras al bando conservador ${ }^{18}$. De ahí que, como indica H. Raguer, entre los dos proyectos que se han dado en la Iglesia contemporánea (el de León XIII, claramente partidario de separar la religión católica de cualquier régimen político, y la de Juan XXIII y el Vaticano II, impulsores de la libertad religiosa y los grandes valores de la sociedad contemporánea), la Iglesia española «no llegaba ni a aceptar la hipótesis de León XIII, que tal vez podía valer para Francia, pero no para la catolicísima España ${ }^{19}$. Por eso, la tesis de la cruzada, cimentada en la excusa de la persecución de la Iglesia, tiene que compensarse y balancearse con la evidencia de que una parte importante de la Iglesia no quiso nunca aceptar la derrota electoral de la derecha y la implantación de la República ${ }^{20}$.

De ahí que, cuando se produce el levantamiento, los obispos se apresuran a posicionarse a su favor, firmando la famosa Carta Colectiva de los obispos españoles, que legitimaba el levantamiento y le confería la condición de cruzada, guerra en defensa de la religión y las buenas costumbres. Desde posturas religiosas conservadoras, siempre se ha pretendido argumentar que el detonante de la guerra fue la persecución religiosa, mientras que los datos que aportan otros historiadores indican que más bien el apoyo de la Iglesia oficial española al levantamiento militar fue una de las circunstancias que encendió la mecha de la persecución por parte de minorías radicales que las autoridades de la República no supieron controlar.

Ello nos lleva a referirnos al espinoso tema de las víctimas religiosas, o mártires, de la guerra civil, tema fundamental para enfocar la acusación

17 Cfr. Gragam, H., o.c., cap. $2^{\circ}$.

18 Cfr. Herrero, Javier, Los orígenes del pensamiento reaccionario español, Barcelona, EDICUSA, 1971 ( $2^{\mathrm{a}}$ ed.: 1973).

19 Raguer, H., o.c., p. 41.

20 Para el detalle de todos estos aspectos, léase entre otros los libros citados de $\mathrm{H}$. Raguer y de H. Graham. 
(quizás la más fuerte) que Ayala arroja sobre GB: el silencio ante los mártires claretianos, sobre todo los de Barbastro, siendo como habían sido compañeros de comunidad, algunos, y antiguos alumnos, muchos de ellos. El primer dato que hay que resaltar es que, contra el mensaje extendido desde el primer momento por la Iglesia oficial consistente en que el bando republicano mataba a clérigos y religiosos, mientras que el bando nacional se comportaba de una forma ejemplar, los datos reflejan lo erróneo, hipócrita y tendencioso de esta forma de ver las cosas. La represión en el terreno franquista, desde el primer momento, fue moneda corriente, y no desmereció en crueldad a lo más inhumano del bando contrario $^{21}$. De ahí que personas, como M. de Unamuno, que apoyó al principio al bando rebelde, pensando que iba a defender los derechos humanos en su territorio, enseguida se desengañó y se desdijo de su postura inicial, convencido de que la guerra era un feroz ajuste de cuentas entre los «hunos y los otros»" Resulta muy ilustrativo a este respecto el testimonio del sacerdote navarro, Marino Ayerra Redín, párroco de Alsasua, quien dejó escritas sus memorias de los años de la guerra y de la crueldad con la que los grupos requetés y falangistas del entorno fusilaban y encarcelaban sin juicio alguno (y a veces sin dejarles el consuelo de la confesión) a sus enemigos ideológicos ${ }^{23}$.

Pero es que además, en el territorio nacional también se persiguió, se apresó y se mató a sacerdotes y religiosos, por el único crimen de defender las ideas del bando contrario. Ayala reconoce que al menos catorce sacerdotes vascos fueron matados por los nacionales, entre los que había también un claretiano (A, 262). Y no vale decir que en un bando fueron más que en otro, porque estaremos de acuerdo en que no es un problema de cantidad, sino de no tener autoridad moral para achacar al contrario lo mismo que están haciendo los tuyos. Ante esta evidencia, es más acertado reflexionar con sensatez y reconocer que, como ocurre en toda guerra civil, la crueldad frente al enemigo, apoyándose siempre en razones que creemos de peso (defensa de la religión, mantenimiento de las buenas costumbres, la unidad de la patria, etc.), se convierte en moneda corriente y en la excusa para tratar de hacer desaparecer para siempre cualquier rastro del otro que nos estorba.

De ahí que el empeño de la Iglesia oficial española en seguir adelante con el proceso de beatificación de los mártires de la cruzada, aprovechando la coyuntura del pontificado de Juan Pablo II, cuando los Papas anteriores (Pío XII, Juan XXIII y Pablo VI) enfriaron conscientemente estos procesos, «resistiendo las presiones procedentes del Estado católico español » ${ }^{24}$, no hace más que confirmar la incapacidad de nuestros dirigentes eclesiales españoles en renunciar a su

\footnotetext{
21 Cfr. Graham, H., o.c., cap. $2^{\circ}$.

22 Cfr. Trapiello, Andrés, Las armas y las letras. Literatura y guerra civil (1936-1949), Barcelona, Edic. Destino, 1994 (3ª ed.: 2010), cap. $2^{\circ}$.

23 Cfr. Ayerra Redín, Marino, Malditos seáis. No me avergoncé del Evangelio, Pamplona, Edit. Mintxoa, 2002 (2 $2^{\mathrm{a}}$ ed.: 2003)

${ }^{24}$ Juliá, Santos, "Víctima y verdugo», El País, 3 de diciembre de 2006, domingo, pp.
} $12-13 ; 12$. 
maniqueísmo moral, y a no reconocer, como indica el historiador Santos Juliá, que la Iglesia fue víctima y verdugo ${ }^{25}$. Nada le costaba honrar a sus víctimas, incluso reconocerlas como mártires para sus fieles, conscientes de que estamos en un terreno vidrioso ${ }^{26}$, pero haciendo un esfuerzo sensato de reconciliación y de tender puentes. Muy otra es la actitud de reconocimiento de los propios errores y comprensión ante los del contrario expresada en estas palabras del militante cristiano del partido comunista, Alfonso Carlos Comín: «Pertenezco a un Partido que ha fusilado héroes y a una Iglesia que ha perseguido a santos $»^{27}$.

De ahí que exigir a GB la condena explícita de la muerte de los mártires claretianos, me resulte una exigencia un tanto extraña. En primer lugar, cuando ocurrieron los hechos él seguía siendo claretiano, y en varias de sus cartas hace referencia a los tristes acontecimientos bélicos que se están sucediendo. ¿Qué más podía decir? Y después de la guerra, entiendo perfectamente que GB se distancie y no haga ninguna referencia a estos sucesos que quiere dejar totalmente a sus espaldas, porque ha sido para él tan dolorosos. Pero en este punto veo en Ayala otra vez el uso de la doble vara de medir. Si se exige una referencia explícita de GB a las víctimas/mártires claretianas/as (se supone que para reconocer su culpa por pertenecer al bando republicano), ¿por qué no exigir a todos los que apoyaron al bando franquista, tanto durante la guerra como en los años posteriores, el reconocimiento explícito de su complicidad en las matanzas y crueldades cometidas en terreno nacional, y en las cárceles franquistas tras la guerra? Porque la crueldad con la que Franco trató a los republicanos durante la guerra, y a los vencidos después de ella, era bien conocida por los dirigentes religiosos, como queda bien corroborada por los investigadores posteriores ${ }^{28}$.

\subsection{Un sacerdote en evolución hacia la democracia republicana}

A GB le pilló la llegada de la República en el momento de transición como profesor de filosofía entre Solsona y la Universidad de Barcelona. Son momentos en que se empiezan a producir actos de violencia anticlerical. Ayala indica que no sabemos cómo vivió GB estos acontecimientos, ya que no se refiere a ello en ninguna de sus cartas $(\mathrm{A}, 156)$. ¿Y por qué tenía que referirse a ello en unas cartas que tenían otros objetivos? Lo curioso es que, al referirse también a la consigna que siguieron los claretianos de Solsona de abstenerse

25 Así titula el artículo citado en la nota anterior. Cfr. CASANOva, Julián, «Guerra Civil y religión», El País, 14 de junio de 2006, p. 17; Id., «Franco, la Iglesia católica y sus mártires», El País, 26 de junio de 2007, p. 15; Raguer, H., "Un canónigo republicano», El País, 23 de febrero de 2007, p. 13; Gallegos Rocafull, J. M., La pequeña grey. Testimonio religioso sobre la Guerra Civil española, Barcelona, Península, 2007.

26 Cfr. Mate, Reyes, «Víctimas o mártires», El País, 8 de mayo de 2007, p. 15.

27 Citado por R. Mate: art. cit.

28 Baste, como un ejemplo, leer los libros de H. Graham (o.c., caps. $2^{\circ}$ y $4^{\circ}$ ) y de $\mathrm{H}$. Raguer (cap. 13). 
en esas votaciones municipales que desembocaron en la proclamación de la República, se pregunta qué hizo GB. «Si G.B. se abstuvo de votar en aquellas elecciones municipales que abrieron la puerta a la República, lo haría por no llamar la atención de los demás, pero en modo alguno compartía las razones que da el cronista de la casa» (A. 156-157). Como vemos, sigue Ayala empeñado en sospechar y en saber las intenciones profundas de GB, y convencido de la «"duplicidad" de vida que vivía en cuestiones de política y de filosofía» (A, 156, comillas del autor). Resulta un tanto difícil concordar con estas afirmaciones, al menos en cuanto al tema político (vamos a dejar el aspecto filosófico), cuando parece evidente que el giro de GB hacía las simpatías republicanas lo va realizando a medida que entra en contacto con el profesorado universitario, que en estos momentos todavía no se ha realizado o se está iniciando, como el mismo Ayala lo reconoce (A, 172). Pero ya hemos dicho que la costumbre de Ayala es, teniendo en cuenta el cambio final, adelantar las sospechas lo más pronto posible; aunque no tenga datos, sólo sospechas. Los datos que tenemos son que, durante el curso 1932-1933, GB da algunas conferencias en la universidad, consiguiendo en junio de 1933 el título de Bachiller, para dejar ya definitivamente su puesto de profesor en Solsona al terminar ese curso, iniciando sus clases en la Universidad de Barcelona. «Los superiores, nos dice Ayala, no sabían de la lucha interior que se estaba librando en GB» (A, 171). Ayala, en cambio, que por lo visto es muy buen psicólogo, sí lo sabe y lo ve bien claro desde el principio. Es que GB era muy hábil para engatusarlos y conseguir de ellos todo lo que quería. Por supuesto que GB se está adentrando en un momento de su vida en que se van a producir importantes transformaciones, pero los cambios no son ni tan claros ni tan rápidos como quiere hacernos creer Ayala, ni siquiera, pienso yo, tan conscientes en el mismo GB como para atribuirle una doble intención y una conducta maquiavélica. Se hallaba, como lo ha expresado en otros escritos posteriores, consciente de que había elementos en filosofía, política y religión, que ya no le convencían, pero estaba muy lejos de saber los nuevos continentes en los que iba a transitar en el futuro. En el ámbito filosófico, él ha llegado a decir que sus estudios en filosofía de la ciencia y el contacto con algunos escritos de Ortega le estaban ayudando a superar el neotomismo ${ }^{29}$; en política, los contactos en la universidad le iban asentando en un camino en el que iba encontrándose más a gusto con sus nuevos convencimientos ideológicos; pero en el aspecto religioso, a tenor de los datos que Ayala nos va mostrando en su libro, y con toda la ambigüedad que queramos, da la impresión de que GB intentó hasta el final permanecer en la orden claretiana, ofreciendo a los superiores el traslado a países de habla inglesa. Eso sí, tenía claro que no podía volver a España, tanto por su oposición al bando nacional, como por su seguridad física. Y en esto, los acontecimientos le dieron la razón, no cayendo en el error, como Besteiro, entre otros, de pensar que cabía en Franco la compasión con los vencidos. En definitiva, querer

29 Cfr. su Autobiografía intelectual, en Confesiones, o.c., pp. 120 y ss. 
hallar dobles intenciones y silencios cómplices en unos momentos en que GB no parece tener claro qué hacer con su vida, me ha parecido siempre una exageración sin fundamentos. Es lo que me ocurre cuando dice Ayala que, a partir de ese momento, GB «se instaló en una "cómoda" duplicidad de vida -buen religioso en el convento y un hombre totalmente laico en la Universidad» (A, 172), a pesar de que dice en otros lugares que llevaba siempre sotana en la universidad, y nos aporta el dato de tres informes totalmente favorables de los superiores de Cervera y Solsona sobre su vida ejemplar (A, 172).

No puedo extenderme sobre los demás elementos de esta etapa previa a la guerra, para poder dedicarme a algunos aspectos de la época del conflicto. Con los títulos oficiales de licenciado y doctor en filosofía, comienza su brillante carrera de profesor de filosofía en la Autónoma de Barcelona, y obtiene también sendas cátedras, en el CEU de Madrid, fundado por Herrera Oria y en la Universidad de Santiago de Compostela. La guerra le sorprende impartiendo cursos de verano del CEU en Santander, y, tras pasar por Bilbao, marcha a Hendaya, y de allí consigue pasar a la zona republicana de Cataluña y llegar a Barcelona. En todas estas etapas quiere ver Ayala contradicciones y conductas sospechosas por parte de GB. Tras conseguir salir de Barcelona, GB recala en París, donde se produce el suceso con el obispo de Calahorra.

Ya he hecho referencia en otro momento anterior a la estrategia de Ayala de preparar al lector, ante acontecimientos claves, con opiniones críticas antes de presentar los hechos. Esto es lo que hace en este suceso a que vamos a referirnos. Durante la estancia del obispo de Calahorra en la comunidad claretiana de la Misión Española de París, se desahogó en diversos diálogos espontáneos con los claretianos, entre los que estaba GB, sobre diversos acontecimientos de la guerra civil (A, 258 y ss.). GB, que estaba colaborando con los republicanos residentes en París, pasó la información para que pudiera ser publicada en La Voz de Madrid, periódico de propaganda republicana, y así se hizo mediante un artículo firmado por Ogier Petreceille. No me voy a extender sobre los diferentes datos del caso, porque se pueden leer en el libro (A, 258-278). Sólo me quiero detener en volver a insistir en el doble rasero con que juzga Ayala a GB: se le denomina felón y poco leal con sus compañeros, y exculpa y comprende totalmente la actitud del obispo.

En el enjuiciamiento de este caso considero que hay que tener en cuenta que estamos en plena guerra. Si juzgáramos este hecho en una situación normal, podríamos reconocer lo incorrecto de hacer públicas unas declaraciones que se hacen en una situación de confidencialidad. Pero en una situación de guerra, en la que la información sobre debilidades del enemigo, aportando pruebas que se negaban públicamente (el bombardeo de Gernika por la aviación alemana al servicio de los franquistas), este tipo de episodios resulta un fenómeno baladí comparado con la falta de escrúpulos a la hora de fusilar sin juicio previo al enemigo. Y sobre todo, lo que me llama la atención es la incapacidad de Ayala para hacer ningún juicio crítico sobre el obispo. El monseñor podrá acusarle de desleal a GB, pero él se comporta como un cobarde y mentiroso, negando lo que ha dicho delante de todos, pensando que se iba a quedar en secreto. Si acusamos a GB de desleal, digamos también que el obispo se defiende mintiendo, por 
miedo (real, por supuesto) a las consecuencias (pérdida de su sede y expulsión del país, si volvía $)^{30}$ que le podían llegar de parte del bando nacional, que no se andaba con tibiezas a la hora de tratar a los enemigos y desafectos ${ }^{31}$. Así, el obispo no sólo acusa a GB de desleal, sino que niega todo lo que aparece en el reportaje periodístico. Si uno lee el episodio sin prejuicios, la conclusión que se saca es evidente: el obispo se ha explayado con toda ingenuidad, advierte que todo eso se ha hecho público, y ante el miedo a las consecuencias, desmiente lo dicho y se desdice de todo. Resulta explicable esa reacción, porque el miedo nos hace reaccionar de forma muy distinta a las situaciones normales. Pero tenemos que ser honestos a la hora de enjuiciar el caso. Y si queremos hacer de jueces de GB, atrevámonos también a enjuiciar con la misma exquisitez al obispo.

Podríamos hablar largo y tendido sobre los problemáticos meses finales de la guerra y de la estancia de GB en París, porque las páginas que Ayala dedica a ello no tienen desperdicio, continuando con sus sospechas, acusaciones de mentira y doblez permanente sobre GB, y haciendo juicios de valor que la mayoría de ellos no se sostienen. No nos queda más que realizar, de forma conclusiva, una reflexión general de esta época de la vida de GB, mostrando que se puede hacer una valoración muy distinta de ella, al mismo tiempo que tenemos que lamentar que nuestro protagonista tuviera que vivir en un ámbito existencial tan duro y tan lleno de contradicciones, que le llevó a tener que abandonar su patria y sus convicciones, para orientar su vida en otras direcciones.

\section{UNA PROFUNDA TRANSFORMACIÓN VITAL QUE SE QUIEBRA}

Como ya lo he dicho más arriba, uno de los documentos más significativos del libro es para mí la carta que escribe el claretiano, P. Ortega, tras encontrarse en Madrid con GB (A. 192). Desde la primera vez que la leí, me impactó profundamente por su profundidad y delicadeza, y consideré que el libro de Ayala hubiera sido totalmente diferente si se hubiera escrito con ese talante de agudeza y comprensión que muestra el P. Ortega en su carta. Ha calado hasta el fondo la situación en la que se halla GB: «Está muy alto — porque es una cosa extraordinaria-, y, sobre todo, está muy solo. Claro que es muy difícil hacerle compañía, porque los hombres, cuando son de cierto nivel, han de tener por atmósfera suya la soledad. No está tanto en querer acompañarle: es preciso poder acompañarle. Esto no quiere decir que no lo necesite. Además, por carácter me parece poco afectivo, aunque muy correcto, muy atento, muy fino» (A, 192). ¡Qué extraordinaria capacidad para calar la situación de una persona, y para expresar tanto en tan pocas líneas!

30 De hecho, y no sólo por este episodio de París, D. Fidel Martínez, obispo de Calahorra, sufrió las antipatías del régimen franquista, y hasta fue objeto de una conspiración contra él. Cfr. Arizmendi, A./De Blas, Patricio, Conspiración contra el obispo de Calahorra. Denuncia y crónica de una canallada, Madrid, EDAF, 2008.

31 Cfr. Graham, H., o.c, cap. $2^{\circ}$. 
Esta carta nos dibuja claramente la situación en la que se va encontrando poco a poco GB. Dotado de una capacidad intelectual extraordinaria, ha tratado de lograr de sus superiores, y lo ha conseguido, debido a una comprensión admirable por parte de ellos (hay que reconocer que sus superiores lo cuidaron y dotaron de medios intelectuales que muy pocas veces se), los permisos y medios necesarios para formarse y para poder dotar a la congregación de los planes y medios necesarios para sus futuros miembros, que pasarán por sus casas de formación. Coincido con Ayala cuando afirma en algún momento que GB se extralimita, con sueños demasiado ideales, en sus planes de estudio para la formación clerical, estudios que son más propios de una universidad que de un seminario. Pero eso nos hace ver que su devoción por el saber, y sus ganas de aportar a su "amada congregación», eran sinceras, y empleaba todo el tiempo y su afán en conseguirlo.

$\mathrm{Y}$ en ese camino, y en medio de tantos esfuerzos, el progresivo avance en el conocimiento tanto de la filosofía como de la ciencia del momento le fue minando sus creencias (en el sentido amplio de Ortega), tanto en el ámbito filosófico como religioso. Lo que sí parece evidente que en sus cartas aflora un entusiasmo extraordinario por el afán de saber, y apenas se mencionan aspectos de su vida espiritual de creyente. Pero ya hemos visto que los informes de sus superiores y compañeros siempre inciden en reconocer que en las relaciones humanas y en el cumplimiento de su vida comunitaria y espiritual era modélico y no había ningún reproche que ponerle.

De ahí que parece razonable afirmar que el momento clave de su vida se produce en el salto a la Universidad de Barcelona, no antes; aunque los elementos para dar ese cambio estaban ya abonados en su interior. Ahora bien, este cambio lo podemos enjuiciar desde el punto de vista desde el que lo hace Ayala (salida de la orden y abandono de su condición de sacerdote y de creyente), o bien desde una postura más amplia y comprensiva, sin ánimo de hacer juicios de valor. Acogiéndome a esta perspectiva segunda, veo que la extraordinaria capacidad intelectual de GB no podía permanecer más tiempo encerrada en el neotomismo, ante los golpes que la ciencia moderna estaba propinando al realismo ingenuo de la cosmovisión aritotélico-tomista y el criticismo kantiano. Igualmente, era inevitable que el contacto con el ambiente intelectual abierto y liberal de la Universidad de Barcelona le abriera los ojos a una mentalidad pluralista tanto en lo sociopolítico como religioso, y se decidiera a defender las tesis republicanas.

La tragedia para GB fue que la superación del tomismo para seguir las tesis de la filosofía contemporánea, tras la Ilustración (algo que hoy día nos parece elemental y de sentido común), así como el poder acogerse a una legítima postura social y política de defender las tesis de la República, sin tener por qué achacarle la responsabilidad de los actos asesinos y antidemocráticos de las minorías extremistas, para realizar con todo ello una síntesis teórica y vital, no era fácil ni posible en aquel momento y en sus circunstancias. La Iglesia oficial no permitía esas síntesis, ni a personas ni a instituciones. Ayala expresa en algún momento que quizás le hubiera ido de otra manera si GB hubiera 
pertenecido a los jesuitas o a los dominicos. Si estamos pensando en el entorno europeo, quizás; pero si vemos el panorama que en ambas instituciones se daba en el entorno español, no creo que hubiera muchas diferencias respecto a las demás congregaciones. De ahí que tengamos que coincidir con Ayala cuando entiende que, aunque no se hubiera producido la guerra civil, la crisis intelectual y espiritual de GB se habría producido tarde o temprano, aunque resulte imposible averiguar cómo y cuándo.

Por eso es tan acertada y clarividente la afirmación del P. Ortega al ver la altura y la soledad en la que se halla GB. Lo admira por la altura intelectual en que se mueve, y por la necesidad que tiene de relacionarse con sus pares intelectuales. De ahí su soledad en la congregación, aunque también la dificultad en acompañarle, dadas sus circunstancias y su carácter. La síntesis que él quisiera construir entre la razón filosófico-científica, crítica e ilustrada, y la fe católica, no le resulta fácil de realizar. Ortega advierte: «Está muy solicitado por distintos medios no católicos, y a él le he visto muy inclinado a ellos. Yo comprendo que es, en cierto modo, necesidad. La orientación que ha dado a sus estudios no es apenas comprendida, y, mucho menos, seguida por los elementos eclesiásticos. Y aun como católicos de España, su espíritu sólo puede encontrar satisfacción de altura entre los otros. (...) ¡Qué lástima que en el campo católico no haya tenido aún más alta y más amplia visión de las cosas! ¡Qué gran elemento el P. David García para formar un foco de alta cultura filosófico-científica de inspiración católica de donde se derrame luego copiosamente a tantas inteligencias preclaras como hoy se están formando en esta hermosa juventud española, nunca como hoy animada por un inmenso afán de saber! En resumidas cuentas: creo que es un Padre a quien deben cuidar mucho; favorecerle mucho..., pero velar por él muy diligentemente, muy amorosamente. Cosa, en verdad, difícil en hombres como él. Pero debe hacerse, porque bien vale la pena» A, 192).

Los acontecimientos nos han mostrado que esos buenos deseos del $\mathrm{P}$. Ortega no se cumplieron, y es posible que no se pudieran cumplir nunca. La situación cultural, social, política y religiosa de la España de entonces no daba para diálogos ni síntesis, sino para separaciones maniqueas y descalificaciones cainitas que desembocaron en una feroz guerra civil, y en una postguerra no menos sanguinaria. En este escrito no he intentado hacer un panegírico de GB, defendiéndole a ultranza de todo. Lo que simplemente pretendo mostrar es que el libro de Ayala, que aporta tanta luz sobre muchos aspectos de esta época tan central en la vida de GB, resulta fallido en gran medida por el talante tan poco comprensivo con el que ha sido escrito. Muy diferente habría resultado si se hubiera hecho desde el talante que nos muestra el P. Ortega. Por eso, pienso que queda todavía por realizar una investigación a fondo sobre estos años tan decisivos para GB y para toda la generación de la guerra. 